\title{
A STUDY OF THE STYLISTIC FEATURES AND EFFECTS OF ENGLISH FOOTBALL NEWS
}

\author{
Jing Huang \\ School of Foreign Languages \\ Dalian University of Technology Dalian, China \\ E-mail: jazlynhuang61 @ 163.com \\ iD https://orcid.org/0000-0002-9571-481X \\ Dr. Shuo Cao \\ Professor \\ School of Foreign Languages \\ Dalian University of Technology Dalian, China \\ E-mail: caoshuo@dlut.edu.cn \\ https://orcid.org/0000-0003-3818-9892 \\ Fang Yue \\ School of Foreign Languages \\ Dalian University of Technology Dalian, China \\ E-mail: yf1101123@163.com \\ iDhttps://orcid.org/0000-0002-2986-9368
}

Received: August 29, $2021 \quad$ Accepted: September 30, $2021 \quad$ Online Published: December 31, 2021

DOI: 10.46281/aijssr.v10i1.1529

URL: https://doi.org/10.46281/aijssr.v10i1.1529

\begin{abstract}
The study investigates the stylistic features of English football news from the perspective of general stylistics. Stylistics, as a discipline based on modern linguistic theories, turns to studying non-literary texts from the perspective of stylistics. The study examines English football news from the three levels of stylistic analysis, namely lexis, syntax and semantics. Compared with other news types, English football news are less attracted to linguistics, and most of the previous studies are focused on the research of the title. This study employs samples of English football news from the official website of the 2018 World Cup in Russia. The findings of this study suggest that at the lexical level, the use of technical terms, abbreviation, nicknames, neologism and numbers highlights the uniqueness of English football news in lexical use, thereby saving space, increasing readability and narrowing the distance between news editors and readers; at the syntactic level, the special stylistic features of English football news are mainly reflected in the unmarked theme and singular form of a plural concept; and the use of rhetorical devices such as metaphor, hyperbole and personification to achieve semantic variation reflects the stylistic features of English football news at the semantic level.
\end{abstract}

Keywords: English Football News, Stylistic Analysis, Stylistic Effect, Stylistic Feature.

JEL Classification Codes: A19, A39, B49, C10, C60. 


\section{Research Background}

\section{INTRODUCTION}

Among all sports in the world, football is known as the "world's first sport". The number of football fans is astounding about half of the world's population. The FIFA World Cup, held every four years, is the most popular major sporting event in the world and the focus of media attention around the world. Taking the 2018 FIFA World Cup Russia as an example, there were 736 athletes from 32 teams participating in this tournament, and over 214 countries and regions broadcast and reported the World Cup. The media plays an important role in spreading the influence of football. It is relying on the widespread of media that the charm of football can be presented to the audience. English football news is the most common way for people to learn about football, which is usually spread on the Internet, newspapers, television or radio. It is the most important way of information dissemination and has penetrated into people's lives.

And stylistics, as a discipline based on modern linguistic theories, turns to study nonliterary texts. However, there are very few theses on the stylistic study of English football news reports, and most of the theses study the stylistic features of political news and financial news. Therefore, the author believes that it is necessary to broaden the field of stylistic research. In addition, among all the researches on English football news, the author finds out that most studies focus on the characteristics or translation of the title. Therefore, this thesis analyzes the stylistic features of English football news of the official website of the 2018 Russia World Cup from the level of lexis, syntax and semantics.

\section{Research Significance and Purpose}

With the vigorous development of football, football news reports play an important role as an important medium for the spread of football matches and football spirits. Those reports have become one of the indispensable media for people in all walks of life to understand the news of football in a timely and effective manner because of its rich language, timely update and rapid dissemination. Stylistic research is also becoming more and more popular in the study of practical subjects, and news reports are one of them. Besides, as a global language, English is the most common way of presenting football news. Therefore, it is of great significance to study the stylistic features of English football news reports.

On the one hand, this study is conducive to enriching and broadening the research perspective and research results of football news and stylistics theories. From the perspective of football news, previous researches on football reports are mostly metaphorical research, rhetorical research, translation studies, which rarely involve stylistic research. Stylistic research pays more attention to the study of literary works in terms of vocabulary and grammar. There are few analyses of football reports, and most of the relevant researches collected are mainly about financial news or international political news.

On the other hand, it can provide a reference for the learning and teaching of football news English and also give hints for the preparation of football English editors and related football English textbooks. With the deepening of the internationalization of English, Chinese English newspaper and periodicals are constantly improving. By analyzing the stylistic features of football news reports on the official website of the World Cup, this thesis allows the editors of news English in China to deeply understand the characteristics of the mainstream English newspapers, and provides a reference for future news editing work, thus promoting the football and other sports communication of China with the outside world to some extent. 
This thesis analyzes the football news reports of the official website of the 2018 World Cup (www.fifa.com/worldcup/). The specific research questions are as follows:

1. What stylistic features are there in English football news reports at the levels of lexis, syntax and semantics on the official website of the World Cup?

2. What are the significances and effects of the stylistic analysis of English football news?

By studying the above two questions, this thesis aims to reflect the stylistic features of English football news reports and investigate the specific language phenomena and characteristics of English football news reports. Furthermore, it provides enlightenment and references for the learning and teaching of football news English, news English editing and textbook writing.

\section{RELEVANT CONCEPTS}

The classification and basic features of English football news should be introduced before summarizing the theoretical framework of this research, based on the definition of style and stylistic, and the levels of stylistic analysis.

\section{Introduction to English Football News}

With the rapid development of football events at home and abroad, the World Cup, Premier League and many other football events have been successfully held, and English football news has received widespread attention all over the world. The following part briefly outlines the definition and classification of English football news, and then introduces its basic features.

\section{Definition and Classification}

To begin with, we have to introduce the definition of NEWS. According to journalism texts, some western experts have defined NEWS as "an account of something real" (Campbell \& Roland, 1961), "something that has actually happened" (Harriss, Johnson \& Leiter, 1981), "truthful and complete accounts of the social world" (Altheide, 1976). The word "news" is derived from "new". The etymological meaning of the word contains "new news" and "new report", hence the core of "news" is "new", that is, news is the important facts that readers should know but do not know.

As a specific type of English, news English has its unique linguistic features and stylistic features. According to Crystal and Davy (1969), news English is a synthesis and blend of many different news writing features. The most basic function of news is to report news events in a timely manner. Therefore, Zhang Jian (1994) believes that news English generally refers to English with news features used in the news, in line with the requirements of news reports and news dissemination. As a branch of news English, English football news is not just a collection of numbers, nor a simple description of victory and failure. English football news is the information about current football events written in English. This may be provided through many different media: word of mouth, printing, postal systems, broadcasting, electronic communication, or through the testimony of observers and witnesses to events.

There are four main types of football news: hard news, feature stories, depth reporting and column (Zhang Jicheng, 2001). Hard news, also called "live news" is to tell readers the process of events in a straightforward manner. Feature stories can be any event related to football, that is, an interesting event that can draw the readers' attention on the spot, rather than grasping the game from a global perspective. The basic difference between hard news and feature stories is that hard news tells readers about the course and outcomes of the game, and feature stories are usually for entertaining readers. Depth reporting attempts to link news events with other events 
or reports; so that news events will contain the author's point of view. The Column is the free land of football news. Columnists can judge, make recommendations and even talk about themselves. Writers have the priority to creatively express personal opinions. Among these four types, hard news relatively shows the universal style of sports news and has objectivity, thus in the present thesis, the author focuses on hard news.

\section{Basic Features}

Because of the difference in field and tenor, English football news has its own unique features. As for the field, football news covers a broad range, including games, clubs, athletes and training. And football news is mainly to meet the interest of football fanciers. Therefore, the language of football news is not as formal as politics, economics and technology. Compared with non-sports English news, English football news reveals its own characteristics:

(a) Football news has a wide range of audiences. With people's strong desire to participate directly or indirectly in football, football news has received widespread attention. Besides football is inspiring and encouraging to readers. (b) Football news is strongly international. There are a lot of international exchanges in football, and football news has become the main means of information transmission for this "international society". (c) Football news is always on schedule, without shifting to an earlier or later date. Different from other events, Football events are predetermined and provided in terms of time and place. In order to ensure fair competition, the competition arena, competitors and time are stipulated and cannot be changed at random.

\section{Introduction to Stylistics}

The thesis studies the stylistic features of English football news reports under the framework of stylistic and other linguistic theories. The purpose of this part is to provide a theoretical framework for stylistic analysis, first analyzing the definition of style and stylistics, and then introducing stylistic analysis.

\section{Style and Stylistics}

The Longman Language Teaching and Applied Linguistics Dictionary points out that stylistics are changes in a person's conversation or writing. Generally speaking, it changes from being casual to being formal based on the situation, the interviewers, the place and the topic being discussed or vice versa. That means the style refers to the linguistic diversity of users in a particular language on different occasions. However, scholars have different views based on different perspectives.

Crystal and Davy (1969) propose four common interpretations of style:

(a) Style refers to a person's unique language habits of speaking or writing, such as Shakespeare's style and Mark Twain's style.

(b) Style refers to the common language habits of a group of people at one time or for a period of time. For example, the style of public speech, legal documents and news discourse.

(c) Style has the meaning of evaluation, which refers to the validity of the expression. This means saying the right words in the right way, such as someone's speech with a specific persuasive style.

(d) Style only refers to the literary language.

Leech and Short (1981) define the term "style" in the following way: 
(a) Style is a way of using language.

(b) Style includes choices made from language expression

(c) Style selection is limited to language selection, involving alternative methods for proposing the same subject.

(d) Style is in terms of specific areas of language use.

In short, style means the language habits of a person or group of people in a particular situation. Different situations tend to produce variants of different language use, which in turn produces different linguistic features. Therefore, style involves the level of discourse context.

As the name suggests, stylistics is a study of style. Since the perspectives of the definition of style have different interpretations, different linguistics and scholars differ in the comprehension of the definition of stylistics. Leech and Short (1981) define stylistics as a study of language use in the field of literature and see it as a collection of linguistics and literature. Turner (1973) argues that stylistics is a part of linguistics and focuses on changes in language applications. Chinese scholar Xu Youzhi (2005) also emphasized in the book English Stylistics Course that modern stylistics is a discipline that explores the style of language use based on the concepts and means of modern linguistics. It generally consists of two parts: general stylistics and literary stylistics. The latter focuses on the study of stylistic features in various literary works, while the former includes the study of the characteristics of various styles. Football news reports in this article belong to general stylistics.

\section{Stylistic Analysis}

Language is seen as a system consisting of multiple units, such as phonetics, vocabulary, and grammar. The English language is composed of its phonetic patterns, grammatical rules and a large number of vocabularies. As a branch of linguistics, stylistics studies the linguistic features of different languages at different levels in a scientific and systematic way. In order to capture the stylistic features of the text, we must strictly describe the attributes of the text and perform stylistic analysis at different levels so that people can better handle any text they want to learn. Crystal and Davy (1969) propose a way to achieve the overall goal of stylistic analysis, that is, to study a particular language or text and to describe and explore it based on a series of interrelated language levels. These levels include phonetics, graphics, syntax, lexis, and semantics. The number and nature of research at each level are determined by the researcher based on the convenience of the work at hand. This thesis will study English football news from the three levels of lexis, syntax and semantics.

\section{STYLISTIC FEATURES AND EFFECTS OF FOOTBALL NEWS}

Discourse is inseparable from context. There are three concepts that are concerned with situational context introduced by Halliday and Hasen (1976). It is the field of discourse, tenor of discourse and mode of discourse. The field of discourse refers to what is going on during the communication process and the social activities actually taking place. The tenor of discourse means the social relationship between the participants. The mode of discourse is the channel or medium of communication. Therefore, the reliability of the research results is taken into consideration, and the author considers the variability of context factors as much as possible, and limits the field of discourse to English football news related to the World Cup from June 14 to July 15, 2018. The mode of discourse is limited to the official website of the Russian World Cup. 
The following part summarizes the stylistic features of English football news from the level of lexis, syntax and semantics.

\section{Lexical Level Features}

The lexical level refers to the choice of a particular word, the position of the word in the sentence and the meaning of the word. In different contexts, individual vocabularies tend to be different patterns, which is closely related to style. Experienced journalists are skilled at dealing with the vocabulary of materials, whether formal or informal, complex or simple. At this point, the choice of words depends not only on the subject, the reader, but also on the author's language ability. The study mainly analyzes English football news reports from these aspects: technical terms, abbreviation, nicknames neologism and number.

\section{Technical Terms}

Technical terms refer to the unified terms for something specific in a particular field. The meaning of the terminology is precise, single, and not emotional, and generally does not need to be understood by context. Each industry has vocabularies and phrase groups dedicated to that field. There are specific words and preferred grammatical forms in the technical field. Some words or a collection of words can even represent one field (Xu Youzhi, 2005). Understanding football terminology is the first step of reading football news. Football news uses a large number of professional terms in the description of various football games. Those words or phrases are the biggest obstacles for laymen, especially second language learners, to understand the texts.

However, "understandability" is the most obvious feature of the technical terms in English football news compared to terms in other fields. In order to continuously expand its influence and market value, almost every sport will try its best to attract more people's interest. Thus, compared with terms in science and economy, the technical words of football are easier to understand. Here are some examples:

(1) Antoine Griezmann's lofted free kick from the French right was nodded into his own net by Mario Mandzukic. (July 15, 2018)

Free kick is a way to restart the game after a foul in a football match. Free kick in football can be divided into direct free kick (the kicker can directly score the ball into the goal of the offending team) and indirect free kick (the kicker must not score directly, and the ball must be touched by other players before entering the goal).

(2) A cross from the French right-hand side was handled by the Croatia No4, with a penalty awarded after a VAR review. (July 15, 2018)

Cross is a technical movement and tactic that is often used in football matches. It refers to a medium-to-long-range pass from a wide area of the field towards the center of the field near the opponent's goal. It intends to create an angle that allows the forwards to aim for the goal more easily. There are four types of cross: chipped cross, in swinging cross, out swinging cross and grounded cross. Penalty is short for "penalty kick". It is a free kick at the goal from the penalty spot, which is awarded to the attacking team after a foul within the penalty area by an opponent. As can be seen from the above examples, technical terms in football are mostly words with special usage. All industries, to different levels of degree, have codes associated with a particular field of activities. The more specialized the field, the more technical words will be. Therefore, the number of technical words involved in different sports news is also different. Among all kinds of sports, the technical terms of football should be relatively more. Below are some more examples: lofted ball, take kick, offside trap, corner area, right back, forward, long pass, 
deceptive movement, overhead kick, level the score and so on. These words make up the unique lexis of English football news.

\section{Abbreviations}

English football news is concise and includes as much news information as possible within a limited space, hence abbreviations are widely used. Abbreviations is a shortened or contracted form of a word or phrase, used to represent the whole. Abbreviations can replace a lengthy or complex set of words or phrases. In this way, it can save the number of words in news, and make the readers feel simple and easy to remember, while making rational use of space. The most common type of abbreviations in English football news is acronyms. Acronyms refer to the word formed from the initial letter or letters of each of the successive parts or major parts of a compound term.

The abbreviations that often appear in English football news are mainly divided into three categories: (a) Names of organizations and events: AFC=Asian Football Confederation, FIFA= Fédération Internationale de Football Association, UEFA $=$ Union of European Football Associations, CSL= Chinese Super League; (b) Names of football clubs: Barca=Barcelona, Juve=Juventus, MUFC=Manchester United Football Club; (c) Conventional football terms: MVP=Most Valuable Person, VAR=Video Assistant Referee, VS=versus.

\section{Nicknames}

The extensive use of nicknames is a unique and interesting stylistic feature in English football news. Nicknames refer to names that are generally accepted by football news practitioners and football audiences in addition to official names. In football news reports, the player's nickname is often used to represent his real name.

(3) and Les Bleus emulate their heroes of 1998 - including coach Didier Deschamps in securing their second World Cup title. (July 15, 2018)

Les Bleus in English means "The Blues". It refers to the France national football team. France national football team is given this nickname by the media and supporters because of the blues shirts each player wear.

(4) Modric certainly believes that every member of the Vatreni squad can leave Russia with heads held high and memories that will last a lifetime. (July 15, 2018)

Vatreni squad refers to Croatia national football team. The Croatian team's home jersey is made up of red and white plaids, so it is called "the Vatreni squad". Unlike most teams" solid or lined shirts, Croatia's shirts are unique on international football stage.

The use of nicknames in football news not only makes the article more vivid, but also gives readers a sense of intimacy. Therefore, compared with other styles of news reports, football reports pay more attention to vividness and life-orientation. The use of nicknames is a way to achieve this goal.

\section{Neologism}

Language has constantly changed with the development of society, so a large number of new words have emerged in the mass media. Neologism refers to new words or words that have acquired a new meaning. The composition of neologism usually includes the old words given new meaning, the use of hyphens to combine two or more words to construct new words, or to directly create new words. Perhaps the tension and excitement of football matches are more 
likely to inspire enthusiasm and inspiration. Journalists of English football news are very good at creating and using neologism. Below are some examples:

(5) It also underscored why..., against Nigeria and a Lionel Messi-spearheaded Argentina, is among the forerunners for the adidas Golden Glove. (July 10, 2018)

Lionel Messi-spearheaded is a compounded new word in which "Lionel Messi" is an Argentine professional football player who serves as captain of Argentine national football team and "spearhead" means to lead an activity or organized effort. This new word succinctly emphasizes the information of the Argentine national football team to the reader.

(6) We spoke afterwards to the Budweiser Man of the Match, a newly-crowned World Cup champion. (July 15, 2018)

Newly-crowned is also a compounded new word which is often found in English football news. These new words are often related to characteristics of sports teams, games and tactics, such as joint-leading, free-kick, sweetly-struck and hat-trick. These neologisms are vivid and full of creativity.

The use of these new words has greatly increased the vividness and appeal of English football news. In addition, news reports pursue novelty and uniqueness, and the use of neologism can give readers a refreshing feeling.

\section{Numbers}

In football news reports, the number contains a lot of information, which is one of the indicators to measure the value of football news reports, and is also a very important stylistic feature. Examples are as follows:

(7) The 32-year-old appeared determined to savour the present before turning his attention to the future. (July 14, 2018)

(8) France have won the 2018 FIFA World Cup Russia after defeating Croatia 4-2 in a thoroughly entertaining Final.... (July 15, 2018)

(9) In both the Champions League final in 2015 and the UEFA EURO 2016 final, I ended up with the taste of defeat. (July 14, 2018)

(10) With four goals in all at Russia 2018, he is France's second highest scorer at a single World Cup after Just Fontaine, who struck an incredible 13 goals at Sweden 1958. (July 15, 2018)

The number in Example 7 is used to describe the football players and is often used to describe the athlete's height, weight, age and so on. The number in Example 8 is used to describe the score of the game, which is common in football news reports; the number in Example 9 is used to describe the concept of time. Football news is known for its timeliness and the accuracy of time is very important in football news. The number in Example 10 is used to describe the record of a certain athlete or club. In football news, these records can be guidance for future predictions of the game.

Through these numbers, readers can quickly grasp the time of the game, the score, the distance, the difficulty of the action and other information. The numbers also help readers get information quickly and comprehensively while reflecting the authenticity of the news.

\section{Syntactic Level Features}

Syntax focuses on the internal structure of sentences and how those sentences function in sequences. Analysis of the syntactic feature in football news is an important step when we analyze the stylistic features of English football news. 
As a secondary type of news English, football news English must conform to the basic characteristics of accurate, brief and intelligible of news English. In addition, due to the timeliness of football news and the limitations of the layout, football news English has formed some characteristics that are different from general English. The comprehensive analysis of the syntactic level of this paper can help English learners understand the sentence characteristics of English football news. The author will conduct the analysis of English football news from two aspects: thematic structure and singular form of a plural concept.

\section{Thematic Structure}

In stylistics, theme refers to the initial unit of a clause. Subject is the person or thing about whom the statement is made. In English football news, the theme and subject of most short sentences are overlapped, which is called unmarked theme, which can make the order of the sentences tend to be normal, reduce the pressure of reading, and meet the requirements of information transmission. Below are some examples:

(11) Ivan Perisic worked tirelessly throughout the 120 minutes, and his goal sparked a Croatian comeback. The Inter Milan man could even have had a decisive brace in normal time, denied only by the woodwork. (July 11, 2018)

In this short paragraph, "Ivan Perisic", "his goal" and "The Inter Milan man" all serve as both the theme and subject of each clauses, which makes the narrative clear and easy to understand, thus saving readers' time and effort in reading. These features account for a large proportion of English football news.

(12) On Saturday they will set about securing third place, which would be the country's best ever World Cup placing. (July 11, 2018)

Marked themes also exist in English football news, but the number of marked themes is relatively small compared with the unmarked theme. Besides, almost all marked themes are adverbial clauses, not objective clauses. This is because the objective theme completely reverses the word order which is full of drama color. The football news reports mainly focus on transmitting information, and do not focus on the description. In addition, the adverbial themes in the football reports are mainly adverbial of time, place, condition and concession, which is used to explain the time, place and necessary conditions of the events. In example8, the subject of the clause is "they" while the theme of the clause is "On Saturday" used to tell readers the time of the game.

\section{Singular form of a Plural Concept}

Like other English news, the syntactic features of simple sentences and extended simple sentences, passive voice, and simple present tense are more used in English football news. However, compared with other news English, the unique syntactic features of English football news are reflected in the singular form of a plural concept. According to English grammar, the singular noun subject must be followed by a singular verb, and the plural noun subject must be followed by a plural verb. But in English football news, when the subject of a sentence is the name of a club or team, predicate verbs often are plural forms. Here are some examples:

(13) Belgium meet France on Tuesday seeking a spot in the World Cup Final. (July 10, 2018)

(14) Croatia have reached their first FIFA World Cup Final, coming from behind to defeat England... the decisive strike. (July 11, 2018)

According to the general grammatical rules, these sentences undoubtedly violate English grammar: the singular form of the noun subject follows the plural form of the predicate verb. But 
in these examples, the singular form of the subject: Belgium refer to Belgium national football team and Croatia refer to Croatian national football team. Their forms are singular, but actually, they include all members of the national team, so the following predicate verbs are in plural form.

\section{Semantic Level Features}

Semantics is devoted to the study of meaning. Semantic deviation refers to "the generation of linguistic effect involves a particular change in the cognitive sense of a language unit, such as a word or phrase" (Hu Zhuanglin, 2000). The level of semantics concentrates on how the cohesive devices, discourse pattern, rhetorical devices contribute to the meaning of the text as a whole. In English football news, semantic deviation is often realized by rhetorical devices, which can make the language vivid and easy to understand. In this article, the writer will focus on rhetorical devices to analyze the meaning of the text as a whole.

\section{Metaphor}

Metaphor is a figure of speech that directly refers to one thing by mentioning another. It may provide clarity or identify hidden similarities between two ideas. Metaphor connects things that seem to be unrelated. It helps to create the appeal that non-visual language does not have, and enables information recipients to understand the spirit of information more vividly and deeply, aiming to make the specific image of the news stand out. Compared with the simile, the use of metaphor is more flexible and more vivid, therefore, metaphor is widely used in English football news. Below are some examples:

(15) The Belgians swarmed all over their opponents going forward, while remaining watertight at the back. (July 10, 2018)

The reporter compares the Belgian football team to a large group of insects. It vividly shows the oppression and fast movement of Belgian football players, creating imaginative images for the readers.

(16) Late in the game, as their opponents pushed forward... the contest, Batshuayi entered the fray. (July 10, 2018)

(17) England primed for midfield battle royale (July 10, 2018)

The above two examples connect the two different fields of the battlefield and football-field, which can not only render the fierce atmosphere of confrontation in the game, but also satisfy people's "heroic complex" and "victory complex"

The use of these metaphors not only allows us to understand the characteristics of the football field, but also highlights and emphasizes the characteristics of football events, providing viewers with a new perspective on football, and inspiring people's imagination and association.

\section{Hyperbole}

Hyperbole also called overstatement is a very common rhetoric device in English football news. Hyperbole is the use of rich imagination to purposefully enlarge or reduce the image features of things on the basis of objective reality. It can highlight the essence of things, strengthen the author's feelings, and arouse the reader's rich imagination and resonance. Here are some examples:

(18) It was only afterwards that we realised the scope of what we did, when we saw the surge of supporters - a sort of human tsunami. (July 12, 2018)

In this example, "tsunami" refers to an extremely large wave in the sea caused by an earthquake. The journalist describes the surge of France's supporters as human tsunami after France won the 
1998 FIFA World Cup. This exaggeration leaves a strong impact on readers and fully demonstrates the success of the French national football team.

(19) I'm not someone who talks a lot, but I do work my socks off. (July 13, 2018)

This word is used to describe Pavard, France's unexpected heroes in the 2018 World Cup. "work my socks off" is a kind of exaggeration, which reveals Pavard's unimaginable efforts out of the games indicating that his hard work will finally get paid off.

3. Personification

Personification is a rhetorical figure that attributes human nature or character to animals, objects or abstract notions. Personification can make readers feel more intimate, enhance the appeal of news, enrich language expression, and make the smooth game process full of life. Below are some examples:

(20) Lifting England's disappointed heads, less than 72 hours after their World Cup dream slipped away, will be a real test for Gareth Southgate. (July 13, 2018)

In this example, "slip away" means to go somewhere quietly and quickly, especially without being noticed. The reporter attributes human behavior to "World Cup", which vividly tells readers that England's dream of World Cup cannot be realized after they were defeated by Belgium.

(21) "It'll go down as a successful World Cup for us, but I'm convinced that even better awaits us in the future." (July 14, 2018)

This sentence is said by Eden Hazard, a famous Belgian footballer, after Belgium won the 2018 FIFA World Cup Russia bronze medal. The word "await" fully demonstrates the optimistic attitude of Eden, indicating that they will not stop and will strive for better results in the ensuing matches. The use of personification allows readers to virtually feel the temperature and emotions of the news content.

\section{CONCLUSION}

For a long time, the research of English football news has not attracted enough attention from scholars. Based on the theory of stylistics, this thesis makes a comprehensive analysis and description of the stylistic features of English football news from three levels. At the lexical level, the use of technical terms, abbreviation, nicknames, neologism and numbers highlights the uniqueness of English football news in lexical use, thereby saving space, increasing readability and narrowing the distance between news editors and readers; at the syntactic level, the special stylistic features of English football news are mainly reflected in the unmarked theme and singular form of a plural concept; the use of rhetorical devices such as metaphor, hyperbole and personification to achieve semantic variation reflects the stylistic features of English football news at the semantic level.

On the theoretical level, this study broadens the research field of English football news and provides guidance for practical stylistic researches. On the practical level, this thesis allows Chinese news English editors to understand the characteristics of English football news in depth, and gives hints for future news editing work, thus promoting the football communication of China with the outside world to some extent.

Although this thesis contributes to the research of English football news, there are still some shortcomings in this thesis: this thesis is confined only to a lexical-, syntactic- and semantic-level stylistic study of English football news reports from a macroscopic perspective. However, due to time and space constraints, the microscopic perspective research at each level will be dealt with in the future. 


\section{AUTHOR CONTRIBUTIONS}

Conceptualization: Jing Huang, Fang Yue

Data Curation: Fang Yue, Jing Huang

Formal Analysis: Jing Huang

Funding Acquisition: Shuo Cao

Project Administration: Shuo Cao

Software: Fang Yue

Validation: Jing Huang, Fang Yue

Writing - Original Draft: Jing Huang

Writing - Review \& Editing: Shuo Cao

\section{CONFLICT OF INTEREST STATEMENT}

The authors declare that they have no competing interests.

\section{ACKNOWLEDGMENTS}

This work was supported by the National Social Science Foundation of China (Grant Number 19BYY088).

\section{REFERENCES}

Altheide, D. L. (1976). Creating Reality: How TV News Distorts Events. Beverly Hills, CA: Sage Publications.

Campbell, L. R., \& Roland, E. W. (1961). How to Report and Write the News. Englewood Cliffs, NJ: Prentice-Hall.

Crystal, D., \& Davy, D. (1969). Investigating English Style. Bloomington, IL: Indiana University Press.

Halliday, M. \& Hasen, R. (1976). Cohesion in English. London: Longman.

Harriss, J., Leiter, K., \& Johnson, S. (1981). The Complete Reporter. New York, NY: Macmillan.

Hu, Z. L. (2000). Theoretical Stylistics. Beijing: Foreign Language Teaching and Research Press.

Leech, G. N. \& Short, M. H. (1981). Style in Fiction. London: Longman.

Turner, G. W. (1973). Stylistics. London: Penguin Books.

Xu, Y. Z. (2005). English Stylistics. Beijing: Higher Education Press.

Zhang, J. (1994). Journalistic English: Style and Analysis. Shanghai: Shanghai Foreign Language Education Press. 
Zhang, J. C. (2001). Practical Sports English. Beijing: World Publishing Corporation

\section{Copyrights}

Copyright for this article is retained by the author(s), with first publication rights granted to the journal. This is an open-access article distributed under the terms and conditions of the Creative Commons Attribution license (https://creativecommons.org/licenses/by/4.0) 